\title{
An Afro-Asian nexus: South African multinational firm experiences in Chinese labour markets - key focus areas
}

\author{
F. Horwitz*, M. Ferguson and I. Rivett \\ Graduate School of Business, University of Cape Town, \\ Private Bag, Rondebosch 7700, Republic of South Africa \\ fhorwitz@gsb.uct.ac.za \\ A. Lee \\ Faculty of Business Administration, Chinese University of Hong Kong, \\ Leung Kau Kui Building, Shatin, New Territories, Hong Kong \\ Received January 2005
}

\begin{abstract}
This exploratory study examines perspectives of multinational corporations (MNCs) from South Africa (SA) in respect of the variables considered important in product and labour markets in China. These include how MNCs first interpret and understand cultural, human capital, regulatory factors and employment practices, before considering how they might adapt to or seek to influence them. A survey of thirteen SA firms operating or trading in these markets and interviews with South Africans who had undertaken exploratory assignments in China, were done. Key factors were identified and evaluated based on relevant literature and research. The following six focus areas were found to be important for business effectiveness in this market: understanding its market complexity, importance of joint venture partners, guanxi relationship networks, human capital, language and culture, and regulatory environment.
\end{abstract}

*To whom all correspondence should be addressed.

\section{Introduction}

China is a sleeping giant...and when she awakes, she shall astonish the world.

Napoleon Bonaparte, 1803.

Current trade between China and Africa is $\$ 12$ billion per annum. Two percent of China's trade is with Africa and 5 percent of the latter's trade is with China. In a bid to make globalisation work for poor countries, China and Africa plan to triple their trade to $\$ 30$ billion over the next three years. (Cape Times, 15/12/2003:20). China is the fastest growing economy and home to one fifth of the world's population (Wells, 1996), with 9.3\% annual GDP growth from 19782003 (Zeng \& Williamson, 2003:1). The World Bank reports that the total value of goods and services has been growing at a double-digit rate for over 20 years and that, by the year 2025, China's economy will account for $25 \%$ of the total world economy. Since Deng Xiaoping's reforms in China in 1978, foreign direct investment has grown to US\$47 billion in 2000 to US\$52.7 billion in 2002 (PriceWaterhouse Coopers, 2002; Lieberthal \&Lieberthal, 2003). In 2002, China became the first country since the 1980 's to attract more Foreign Direct Investment (FDI) in a year than the United States (Lieberthal \& Lieberthal, 2003:1). Given the complex nature of doing business in China, most multinationals are quite myopic about the country (Zeng \& Williamson, 2003). The size, complexity and diversity of these markets have important implications for all aspects of business, from marketing techniques and human resource management, to business strategy, and cultural adaptation. China is not a single market of 1.3 billion people, but a collection of highly differentiated markets represented by geographical location (Stuttard, 2000). There are sharp contrasts between highly developed urban markets, and the rural poor. Residents of the east coast of China (Guangdong, Fujien, Zhejiang and Jiangsu provinces), and around Shanghai enjoy a standard of living and purchasing power 5 to 10 times that of poorer regions.

\section{Significance of the research}

Studies of developing and transitional economies are of great interest to policy makers and scholars. The concern is to enquire about relationships among a group of social phenomena and variables which will provide insight for the orientation of efforts, organisational strategy and policymaking (Xiao, \& Lo, 2003). China is clearly an attractive target for foreign investment due to sustained economic growth over the past five years, its market size, and also because it now "profoundly affects the competitive capabilities of all multinational corporations and direct trade given its low-cost, low-price manufacturing capability' (Lieberthal \& Lieberthal, 2003:1-2). There is considerable competition between foreign companies who regard China as the biggest emergent market. There is also competition from increasingly entrepreneurial Chinese firms. However, a critical question is how foreign firms entering Chinese markets deal with the complex political-economy, labour markets, and institutional, cultural and human capital variables. It is posited that the most successful foreign investor enterprises in China are those who adapt to the 
unique conditions of the Chinese market. They have an intimate understanding of its political economy, regulatory environment and culture, and adapt their brands and business practices accordingly. South African firms are increasingly investing and doing business in China. Some 18 SA MNCs are amongst the top 200 emergent market companies (Morgan Stanley Capital International Inc., 2003). Several of these such as SAB Miller have joint venture operations, investments and growing market share in China. However, China presents a number of challenges to foreign investors, due to its culture, political context, labour market structure and history. This research aims to identify key focus areas experienced by SA firms in Chinese markets. This exploratory study provides a basis for further survey and qualitative research in this area.

\section{Literature review}

\section{Market reforms in the Chinese political economy}

The diversity, size and complexity of China have often reduced the ability of foreign investors to predict the timing of investments for growth in its markets. The Economist Intelligence Unit (2001) notes the importance of relationship-building, first understanding the diverse nature of local markets and overcoming regulatory hurdles before large-scale capital investment in fixed assets and resources are made. Billions of dollars are being spent upgrading facilities and improving infrastructure following decades as a closed economy with a poor transportation system, weak support services and inadequate communication networks (Wong, 1995). This investment in infrastructure is an important consideration when selecting an operating base. Mock, Wong and Lee (2002) and Morrison, Conaway and Douress (2002) cite rapid price inflation, corruption, layoffs from privatising state-run enterprises, the growing gap between coastal and interior regions, and economic disparities between rural and urban areas, as factors contributing to a degree of social discord. The process of protecting intellectual property rights and prosecuting counterfeiters is an arduous task with no guarantee of success (Stuttard, 2000).

\section{The importance of relationships}

Guanxi is good for you and for me. It is based on a mutual benefit principle. We must have mutual interests and shared interests. We must both have what the other wants and the capability of carrying out our agreements. We must also trust each other.

Chinese manager, Fuzhou Province Abramson et al. (1999)

Wong (1995) cites guanxi as a key aspect of Chinese culture that needs to be understood when doing business there. Guanxi means connections or relationships, and describes the intricate network of relationships that dictate the behaviour of individuals within groups including rights and responsibilities, It is a 'process whereby each side seeks to establish who the other is, whom the other knows, and whether they are respectively able to deliver what each promises' (Stuttard, 2000). A company without guanxi may experience resistance from groups that are necessary for its success. This may increase the red tape that is part of doing business in China (Abramson \& Ai, 1999; Chen \& Godkin, 2001). Not that networking and relationship-building is unique to China, but the lack of legal and administrative transparency means that relationships with relevant officials of appropriate rank are often key to achieving commercial goals. Foreign companies often underestimate the importance of guanxi when transacting business and the time needed to build these relationships. Relationship building with government officials, administrators, potential joint venture partners and employees are often key to achieving commercial success (Ji, 2003). But guanxi networks alone are not sufficient to provide a source of sustained competitive advantage for foreign companies operating in China (Tsang, 1998).

China opened its doors to foreign investors in 1978, but the 'iron rice bowl' system of guaranteed lifelong employment, prevalent in Chinese society during the Cultural Revolution, only gave way to a more market-oriented labour contract system with the introduction of the 1994 Labour Law (Warner, Goodall \& Ding, 2002). Even then, these writers explain that foreign investors were constrained by both the emergent nature of the labour market and the legacy of cradle-to-grave employment practices in Chinese joint venture partners. Thirty years of state owned, centrally planned and regulated production, in a non-competitive market left China with a large administrator cadre rather than professionally trained managers, though entrepreneurship is rapidly increasing. Wong and Maher (1997) identified management and entrepreneurial development the most significant challenge facing foreign investors in China.

\section{Negotiating joint venture partnerships}

Foreign investors in China hope for a financial return on the investments they make. They seek a return, perhaps over a long time frame, from access to the large market and from the lower cost of labour. On the other hand, Chinese joint venture partners want technology and know-how, together with capital and modern equipment, and they invariably expect dividends immediately.

Kent Watson, PriceWaterhouseCoopers

(Stuttard, 2000)

Liebethal and Lieberthal (2003) posit that a multinational firm's operations in China evolve through three distinct phases, each with characteristic goals, structures and management needs. These are the periods of entry, country development and global integration. Each of these phases require consideration of changing goals of the firm over time, role of a China office or manufacturing/operations entity and profile of a suitable China manager. Agenbag (2001) concludes that SA's relatively short diplomatic relationship with China, certain cultural differences and lack of experience in China, would encourage local firms to consider joint ventures, despite the weak intellectual property protection and the significant market potential. His study suggested establishing a representative office as a base for the first phase of entry, to do market research, establish relationships with the government, customers and potential 
partners. It is almost impossible for a foreign company to do business in China without the assistance of a Chinese partner (Wong \& Maher, 1997). This is largely due to the different manner in which business is conducted in China and includes aspects such as cultural, legal, government and economic issues. Joint ventures remain a primary option for foreign companies entering China (Wong, 1995; Stuttard, 2000). Options range from contractual joint ventures (CJV), to equity joint ventures (EJV) or even as wholly foreign owned enterprises (WFOE). Government has become more flexible with regard to the choice of Chinese partner. Local investment, awareness of and experience with the changing Chinese business environment, guanxi relationships, and informal interaction patterns for obtaining information represent key success factors foreign firms.

Culture has a large impact on the negotiation process in China (Ma et al., 2002 and Selmer (2001). Differing expectations of the relationship may occur. Chinese partners may resent having to pay in perpetuity for intellectual property incorporated at the outset, while foreign partners may resent sharing hard-earned profits with Chinese partners who contribute little beyond the hand-holding through the initial licensing process. The tension is further strained by an inherent Chinese mistrust of foreigners, and a sense of cultural superiority, due to a rich cultural history. The sentiment is summed up by the late premier Deng Xiaoping in his adage - "Let foreign things serve China.". This explains the Chinese focus on advantages for themselves in a business transaction, rather than seeking a win-win situation for both parties. (Wong, 1995). The Chinese expression, "to share the same bed but to have different dreams” is often apt.

These disparities often lead to dissolution of joint ventures (Stuttard 2000). Foreign investors in China seek a return, particularly over the long term from access to the large market and from the lower cost of labour. Chinese joint venture partners seek technology transfer, training of local employees and know-how, together with capital and modern equipment, and expect swift dividends. Differing expectations of anticipated gains must be thoroughly explored and carefully negotiated. An agreement is regarded as a snapshot of the current reality, and an indication of good faith and intentions, rather than as a binding commitment. It is seen as a basis for future negotiation, but not used as a threat or coercive measure by foreign companies. Sun yung refers to the level of trust between parties and face is the visible evidence that one can be trusted - both play an integral role in every business transaction in China (Wong, 1995). Face arises from seniority, status in the social hierarchy, education, heritage, wealth, good deeds, charisma, personal integrity, and connections - all of which may put a foreigner at a disadvantage in negotiations. Loss of face may be more serious for Chinese managers than their Western counterparts (Chen \& Godkin, 2001).

Gou Qing is the seen as the 'Chinese way' of doing things. The concept has been a part of Chinese culture for centuries and is sometimes used as measurement when new ideas are introduced into China. An example of gou qing is the state decree of limiting families to one child. This in turn influenced the spending patterns of families and should considered when customising marketing messages for the Chinese market (Yan, 1994). The danger in believing that there is a single amorphous market becomes apparent when selecting specific geographic target markets. A number of factors have contributed towards what can only be described as a fragmented market and combined with variable infrastructure makes the choice of geographic markets a critical decision in joint venture marketing strategy.

\section{Cultural sensitivity, human capital and expatriate management}

The impact that different cultures have on ethics and the manner in which this affects business is of particular importance. Western approaches to management have to be adapted for the Chinese market (Chen \& Godkin, 2001; Pitta, Fung \& Isberg, 1999). The unique culture and history of China have resulted in organisational behaviour that does not readily fit Western management models (Wong \& Maher, 1997). The impact that culture has on ethics and the manner in which this affects business is of particular importance. Nevertheless, some firms report that western and Japanese style management practices apply in China with adaptation for local context and cultural differences. Competitive and individualistic managerial styles do not sit comfortably in a culture where harmony based on Confucian tenets remains important. However, research also shows that younger Chinese employees are more individualist and entrepreneurial (Chen \& Godkin, 2001, Ma, Wang, Jaeger, Anderson, Want \& Saunders, 2002). In their interviews with top company officials they discovered that leading US companies in China apply similar management principles in China as they do in other countries.

Similarly there appears to be a strong relationship between the performance of employees and the use of individual rewards and appraisal (Bjorkman \& Xiucheng, 2002). To be successful manager in China, an individual would benefit from learning Mandarin, to listen and learn from local line managers and Chinese nationals, to remain patient and keep a low profile (Whiteley, 1998). Expatriate managers who regard Chinese colleagues with disdain, seeing the relationship as a one-way transfer of knowledge, technology and capital, deny themselves the opportunity to understand the Chinese way. Evidently, the combined effect of factors like internal pressure to perform, the competitive nature of the Chinese environment, distrust from locals and a work culture that vastly different from their experiences limits the ability of expatriates to manage successfully (Wong \& Maher, 1997). Human capital is a key aspect of any venture into China. Successful companies in China have invested time and money in preparing potential expatriate managers to oversee operations and more specifically developing their cultural literacy (Landry, 1997). Foreign firms increase the job satisfaction of expatriate managers and adaptability to Chinese conditions, by ensuring that expatriate training and cross cultural education includes preliminary visits, family counselling and personal coaching (Selmer, 2002).

Horwitz, Kamoche \& Chew (2002) identify crossvergence or cross-cultural diffusion of high performance work 
practices - as a developing trend in international human resource management and the need for skills development amongst Chinese managers provides an excellent opportunity to share best practises from South Africa. Zhu and Dowling (2002) attribute some of the current reforms in personnel practice to convergence with Western practices. The increased short-term costs of training Chinese managers are outweighed by the long-term benefits that this approach can provide. Wong and Maher (1997) warn however, of increased job-hopping by bright young executives as demand for their skills increases. More recently, Chiu (2002) surveyed employees' commitment to their organisation, and found no difference between joint ventures and state enterprises. This would suggest that foreign companies need to provide more than training, in order to retain key Chinese staff.

Localisation is an expectation and reduces the costly relocation of expatriates, while providing career development for Chinese nationals. The level of training required calls for significant expenditure, but must be weighed against 'hardship' premiums sought by expatriate managers, and their work and lifestyle adjustment. Chinese managers are however, beginning to replace expatriates. The challenge is empowering Chinese recruits to develop critical, independent thinking and risk-taking capabilities traits not widely prevalent in previous local protocols. The move to an open market economy is resulting in changes to human resource policies (Zhu \& Dowling, 2002). These changes include the following aspects: increased emphasis on individual competency rather than political background; use of employment testing in place of personal interviews; alternative mediums for attracting potential employees such as advertising and increased responsibility by business units for staffing issues. The method of learning in China, through rote memory, will not be sufficient to meet this challenge and needs to be developed if Chinese employees are to satisfy the demands of globalisation (Schiller, 2001).

\section{The regulatory environment}

China does not yet have a unified code of law and it is currently devolving authority to a provincial level. Official approval is required for many aspects of Chinese life, such as securing employment in a different region. Officials have relative freedom in implementing increasingly devolved regulations. Inconsistent interpretation of laws between central, provincial and local authorities occurs (Stuttard, 2000). This complicates long-term planning for foreign firms when plans are based on subjective governmental authorisation. Relationships with those who formulate the policies may help attain a favourable outcome of the interpretation, though there is a growing indication that a new generation of Chinese managers is unwilling to tolerate corrupt practices (Wong \& Maher, 1997).

Despite a somewhat opaque regulatory framework, practice may precede regulation. Westerners often view a signed contract as an ironclad oath of performance enforceable by law. A contract may be seen by a Chinese partner as a snapshot of mutual understanding and good faith, along with an implied commitment to resolve potential future differences between friends. A written contract provides a basis from which to negotiate and is not immutable. As a result changes to the contract are often requested as the business transaction unfolds. Legal contracts do not therefore define business relationships but are viewed by Chinese as a beginning of business dealings, making trust and respect more important in the long term. This emphasis on trust over contractual obligation is a key success factor where firms using less formal interaction patterns and coordination achieved higher performance (Abramson \& Ai, 1999). Foreign companies may allow for the regulatory costs associated with operating in China, but these costs are subject to change and some are peculiar to China, for example, partnering costs and extra margins paid to statelicensed importers, distributors and retailers. Brandenburger and Nalebuff (1995) argue a need to play an active role in the development of regulations through relationships with regulatory officials.

The Chinese market is changeable and a long term view is essential - a 'proceed and pause' approach has often been adopted due to the rapidly changing conditions and within a long term commitment to the Chinese market, with profits deferred to the longer term (Wong \& Maher, 1997). In summary key variables important in conducting business in China include: understanding the market, the regulatory environment, importance of relationships, a shortage of qualified management, intense competition, importance of government, and joint venture partners. Further factors include: conducting research and due diligence, choice of joint venture partner, ensuring the right approach to the market, use of expatriate management, localisation, developing a culture of change in employees, building trust relationships, managing costs and making a long term commitment to the Chinese market. In the following section the research methodology will be discussed, focussing on exploring these factors in relation to experiences of SA firms.

\section{Research methodology}

Following the above literature review, there is consensus regarding important focus areas for foreign firms operating in China. There is however, a paucity of published literature regarding SA companies operating in China. This exploratory research proposes that the perspectives presented in literature, regarding focus areas for foreign companies in China, are consistent with those of SA firms operating in these markets.

\section{Sample selection}

Companies are not required to register with the Chinese Embassy in SA, or the SA Embassy in China. As there was no authoritative source of contacts for this research, convenience sampling was used. This is apt for pilot studies or exploratory research (Saunders, Lewis \& Thornhill, 1997). Semi-structured questionnaires were sent electronically to officials of SA firms in China. Many of these firms are members of the South Africa China Business Association ('SACBA'). These firms were invited to participate in the survey. Other responses were obtained through 'snowball' sampling i.e. introductions made during the course of this study. Executives from a total of 32 
companies were invited to participate in the survey. Thirteen responses from SA firms, or their Chinese joint ventures were obtained.

This exploratory research, seeks to understand the perspectives of SA organisations regarding factors important in the cross cultural adaptation in China. Qualitative comparison of experiential interpretations and insights using mainly non-standardised data for conceptual and content analysis is apt. The qualitative approach is reinforced through the use of a research proposition, rather than a clearly defined research hypothesis. In qualitative research, the holistic representation of the data is more important than the individual items (Saunders et al., 1997). Questions were constructed following tenets for formulating cross-cultural research questions, for example questions about crosscultural dimensions to a management research question being meaningful for both managers and academic audiences (Usunier, 1998).

\section{Data collection and analysis}

A questionnaire was designed using both structured and semi-structured or open-ended questions based on the literature. For the former, respondents were asked to assign a rating to each individual factor (Leedy, 1993). Respondents were able to assess each factor on its relevance, rather than an arbitrary ranking of factors. In addition to identifying key factors from the literature, respondents were asked to list their five most important insights, in order of relative importance, which might be valuable for SA firms considering the Chinese market. Additional questions were used to clarify data and obtain additional insights about perceived relative advantages or disadvantages South Africans have in China.

Categorical qualitative data was determined by the standardised questions in the questionnaire. Data was then collated and presented in three sections: (1) Respondent details: information describing the respondent companies (2) Success factors: with individual ratings for each of the different factors identified. Ratings were aggregated and factors were ranked according to aggregate size. Additional factors mentioned by respondents were presented and discussed separately, and (3) Constraints \& Recommendations: data obtained in these unstructured sections were clustered according to key terms, themes and patterns that emerged, as recommended by Saunders et al. (1997). The use of software packages (e.g. NUD-ist) to conduct the content analysis was considered but was not used due to the small sample size.

\section{Research limitations}

There lack of an authoritative source of contact details of SA firms in China precluded the researchers from establishing the exact size of the target population, with the result that it is not possible to establish the statistical significance of the research sample. This constraint excluded random sampling in favour of convenience sampling. The exploratory nature of the research dictated that it be qualitative in nature requiring firms to complete semi-structured questionnaires and submit these via the internet, email or personally.

\section{Analysis of findings}

\section{Respondent companies}

Thirteen SA firms or their joint ventures in China, participated (40\% of the 32 companies invited). The first section of the survey form requested descriptive details of the respondent firm (Table 1). Respondents were from a diverse cross-section of firms in sectors ranging from mining to professional services; approximately 50\% were joint ventures with Chinese partners, while others were solely owned SA firms; the number of years of operating in China ranged from 1.5 to 20 ; SA firms were predominantly staffed by Chinese nationals.

\section{Performance success factors}

Respondents were asked to rate each of the factors identified in Stuttard (2000) for success of foreign companies in China on a scale from 1 to 10 (with 1 as the most critical for success, and 10 as the least critical). Ratings were then inverted for the purpose of presentation. The inverted ratings for each of the factors were aggregated in order to determine an overall ranking (Figure 1 below).

Ratings fell within a relatively narrow band in the upper half of the range, from 136 for Regulations to 89 for Technology. The maximum potential aggregate for any factor was 160 , combining a maximum rating of 10 by each of the 16 respondents (representing 13 companies). This indicates that respondents supported the selection of factors as critical for business success in China. In particular, there was a difference of only seven rating points between the top seven factors. Regulations, Right Partner and Cultural Sensitivity were rated highest on aggregate, followed closely by Market Research, Flexibility, Ownership, and Guanxi. A Long-term View, Localisation, Capital Input and Technology transfer were deemed slightly less important.

Respondents also indicated other factors considered important (Table 2). Some of the additional factors highlight nuances of those in the original list, and there are some new insights, such as 'Selling what is going on in China clearly back to home office', emphasizing the importance of communication. However, the theme common to a number of the additional success factors mentioned is that of guanxi - relationship building through shared understanding. The factors point to the importance of regular, open communication with all stakeholders - partners, government officials, distributors, customers, and the home office, supported by visible displays of commitment. 
Table 1: Descriptive details of companies represented by respondents

\begin{tabular}{|c|c|c|c|c|c|}
\hline \multirow{2}{*}{ Company } & \multirow{2}{*}{$\begin{array}{c}\text { Industry } \\
\text { sector }\end{array}$} & \multirow{2}{*}{$\begin{array}{c}\text { Ownership } \\
\text { structure }\end{array}$} & \multirow{2}{*}{$\begin{array}{c}\text { Years } \\
\text { in China }\end{array}$} & \multicolumn{2}{|c|}{ Employees } \\
\hline & & & & Expatriates & Nationals \\
\hline Alexander Forbes Limited & Insurance Broking & Joint Venture & 7 & 0 & 2 \\
\hline Anglo American & Mining & Joint Venture & 5 & 8 & 300 \\
\hline International SOS & Health Care & Joint Venture & 15 & 40 & 280 \\
\hline Kumba Resources & Mining/Metals & Joint Venture & 13 & 2 & 3 \\
\hline MIH Asia & Electronic Media (PayTV) & Sole Ownership & 5 & 8 & 50 \\
\hline not disclosed & Financial Services & Joint Venture & 7.5 & 30 & 700 \\
\hline Nedbank Limited & Finance & Sole Ownership & 9 & 0 & 3 \\
\hline One Stop Services & Tourism/Importers/Exporters & Sole Ownership & 2 & 2 & 1 \\
\hline $\begin{array}{c}\begin{array}{c}\text { Pricewaterhouse } \\
\text { Coopers }\end{array} \\
\end{array}$ & Professional Services & Sole Ownership & 12 & 400 & 3,900 \\
\hline SABMiller & Beverage/ beer industry & Joint Venture & 8 & 14 & 25,000 \\
\hline Sappi Trading & Pulp \& Paper & Sole Ownership & 20 & 1 & 3 \\
\hline Sasol Chemicals Pacific & Petrochemicals & Sole Ownership & 12 & 2 & 150 \\
\hline Tellumat & Telecoms/IT & Joint Venture & 1.5 & 0 & 130 \\
\hline
\end{tabular}

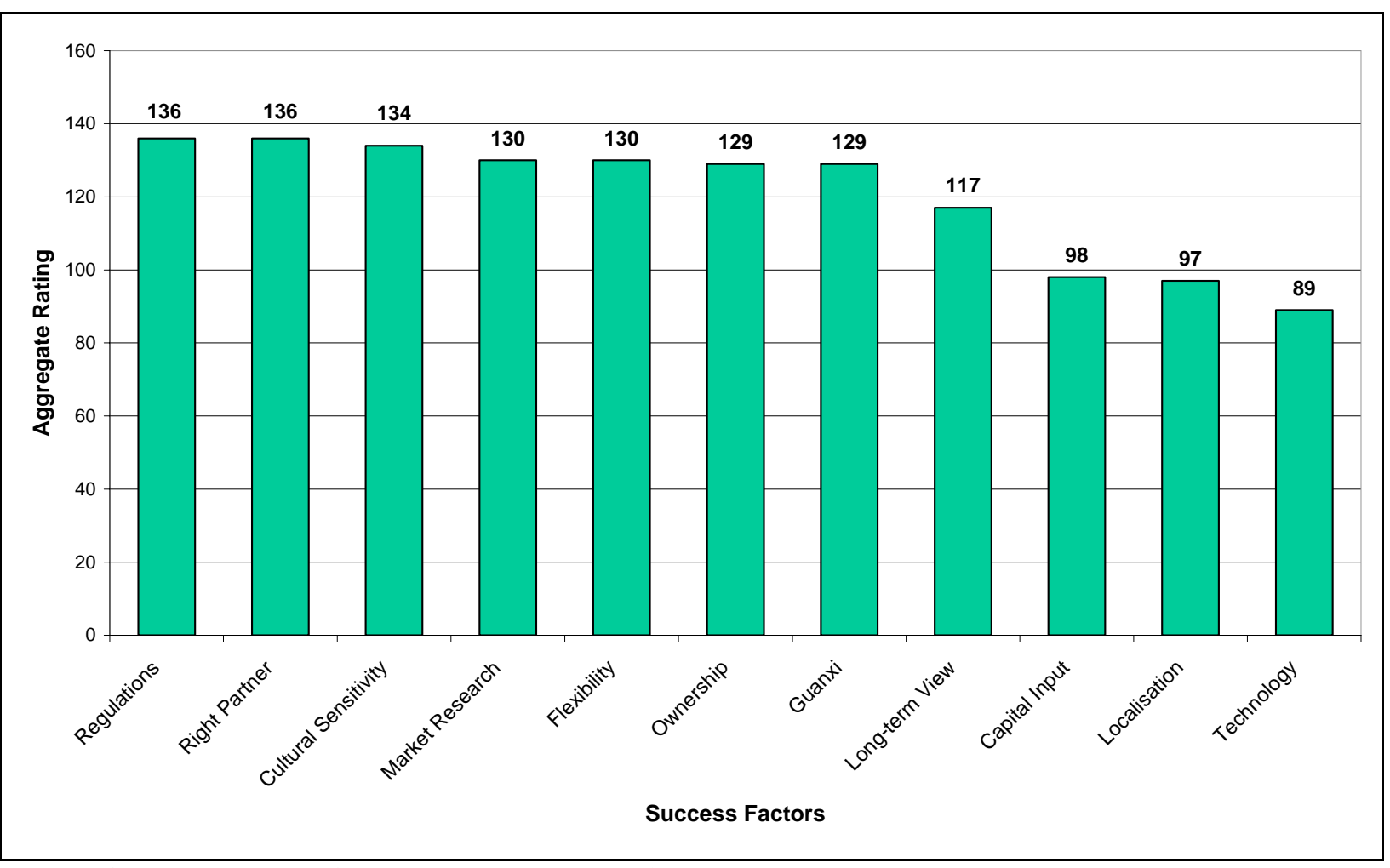

Figure 1: Performance success factors and aggregate ratings. 
Table 2: Additional success factors with inverted ratings.

\begin{tabular}{l|c}
\hline Additional Success Factors Identified & Rating \\
\hline Ensuring own staff are culturally sensitive - if not move them & 10 \\
quickly & 10 \\
Selling what is going on in China clearly back to home office & 10 \\
Cost competitiveness of process and systems & 10 \\
Identify the right parties to work with & 10 \\
Establishing multiple channels to market & 10 \\
Investment to the extent of paying for regulatory certification & 9 \\
Really understanding the your markets' potential - don't & 8 \\
overestimate ! & 8 \\
Aligning all stakeholder expectations & 8 \\
Work with Chinese companies with International experience & 8 \\
Local manufacturing & 8 \\
Find a good Chinese consultant/advisor & 6 \\
Maximise interface time with customers & 5 \\
Making your head office understand the opportunities in China & \\
Commit to the market through both lean and good periods &
\end{tabular}

\section{Factors hindering foreign enterprise in China}

Respondents were then asked to list the 5 constraints that had the greatest impact on the performance of the company in the Chinese market, ranked from 1 [high] to 5 [low]. Again, rankings were inverted for the purpose of presentation, by subtracting each rating from 6 , in order to assign the highest weighting to the most significant constraints. The constraints were then clustered, based on key words and patterns that emerged in the data, and the weightings aggregated in order to determine relative weighting for each group. The relative ranking of the clusters identified is presented in Figure 2 below.

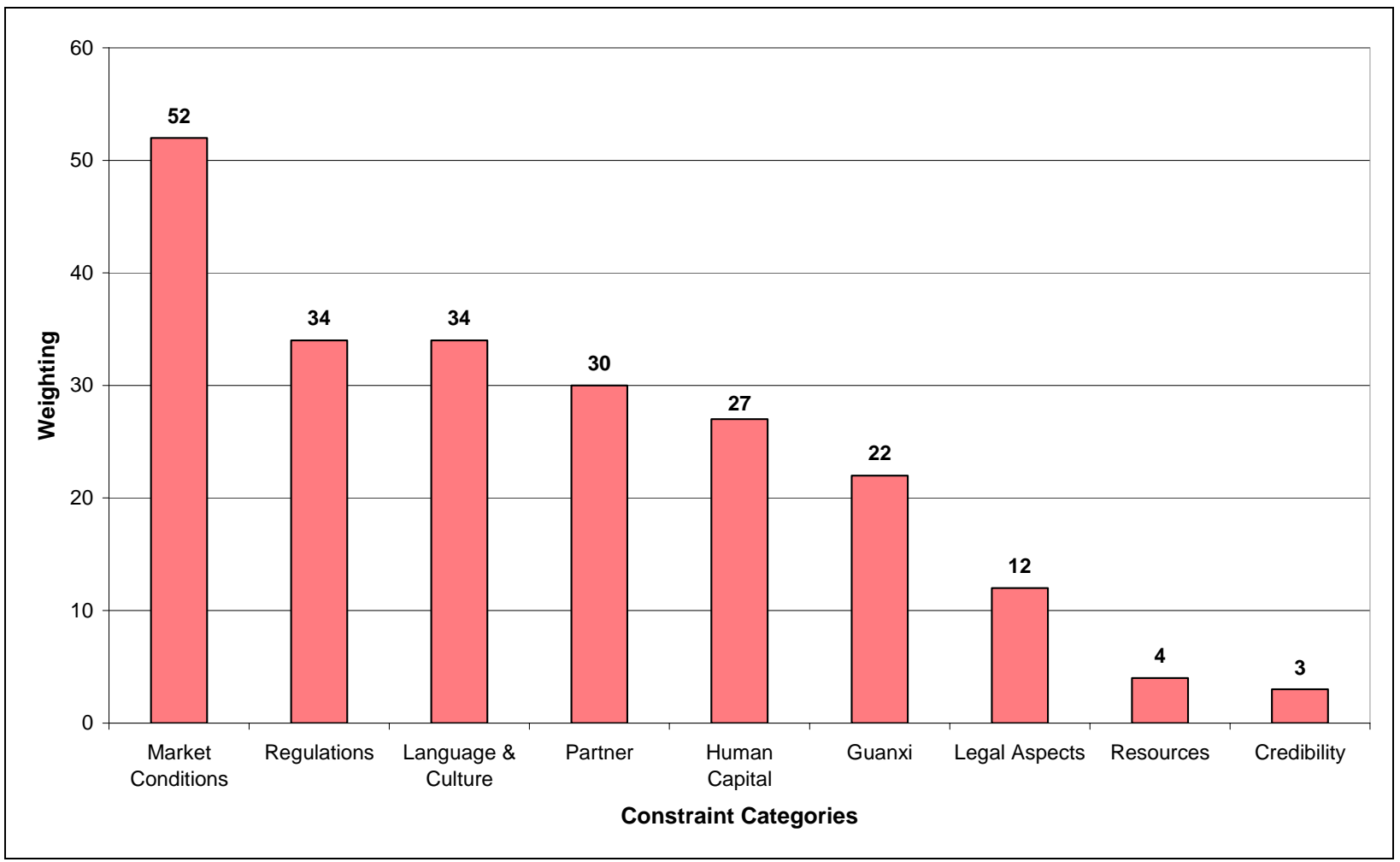

Figure 2: Constraint clusters and aggregate weightings.

The keywords used to represent the constraint categories identified, in the figure, are explained here: Market Conditions - unique market factors found in the Chinese market; Regulations - complex and dynamic nature of the regulatory environment; Language \& Culture - different language, culture and negotiation techniques; Partnerships different expectations and philosophies within a joint venture; Human Capital - availability, retention and training of staff including local versus expatriate deployment; Guanxi - building trust through relationships with relevant stakeholders; Legal and regulatory Aspects - understand the regulatory and legal environment and compliance; Resources - financially and social support; and Credibility lack of credibility and service/product not understood.

Market conditions appear as the most significant constraint for foreign companies in China, with an aggregate weighting of 53. In contrast, companies experienced fewer problems with legal aspects, resources and credibility, with low aggregate weightings of 12 , four and three respectively. This may be attributed to the fact that the most of the companies surveyed are significant multi-nationals in their own right, with access to substantial resources. Responses in the Market Conditions cluster point to the fragmented nature of China's regional markets, poor transport infrastructure, low disposable income levels and poor brand consciousness, as the major constraints facing the companies surveyed. A key message highlighted is not to view the China market as a single amorphous market but rather as a diverse grouping of smaller dynamic markets.

The Regulations cluster, although lower than the Market Conditions cluster (18 points), is indicated by three respondents as the most important constraint to doing business in China (weighting of 5). This factor is mentioned 10 times by the 16 respondents. Regulations can be a serious 
constraint to any business and this seems particularly true in the context of China where the Chinese government plays a dominant role in business activities.

The Language \& Culture cluster is as significant as the Regulations cluster, and is referred to 10 times. The constraint of not being able to communicate in the native language of Chinese business people and not understanding the vastly different cultural context is raised here. Respondents pointed out the importance of patience and protocol when interacting with the Chinese.

The Partner cluster is only mentioned seven times, but in five of these it is identified as the most important constraint in to doing business in China (weighting of 5). This may allude to the significant consequences of a poor choice of joint venture partner. The Human Capital cluster is rated as the fifth most important constraint to doing business in China, with 10 references. This constraint underlines the limited availability of suitably trained locals, specifically those with appropriate management skills. Closer inspection of the guanxi relationship cluster reveals two reasons for its significance. Firstly, great value is placed on the importance of network relationships in Chinese society and business for access for example to key decision makers, the right contacts for joint ventures, prospective to customers, potential suppliers. Secondly, relationships are established and maintained very differently in China.
The smallest three clusters of Legal Aspects, Resources and Credibility are referred to the least number of times, indicating that they are seen as specific to a few companies. Legal aspects include issues relating to extraction from JV situations to sole ownership and non-compliance with contract obligations. Of interest is that one respondent indicated Legal Aspects as the most important constraint to doing business in China (weighting of 5). This may be due to a specific legal situation experienced.

\section{Recommended focus areas}

Respondents were asked to recommend the five focus areas they felt would be most important for foreign companies considering the Chinese market, ranked from 1 [high] to 5 [low]. Rankings were inverted for the purpose of presentation, by subtracting each rating from 6 , in order to assign the highest weighting to the most significant focus area. The focus areas were then clustered, based on key words and patterns that emerged in the data, and the weightings aggregated in order to determine relative weighting for each cluster. The results are presented in Figure 3 below.

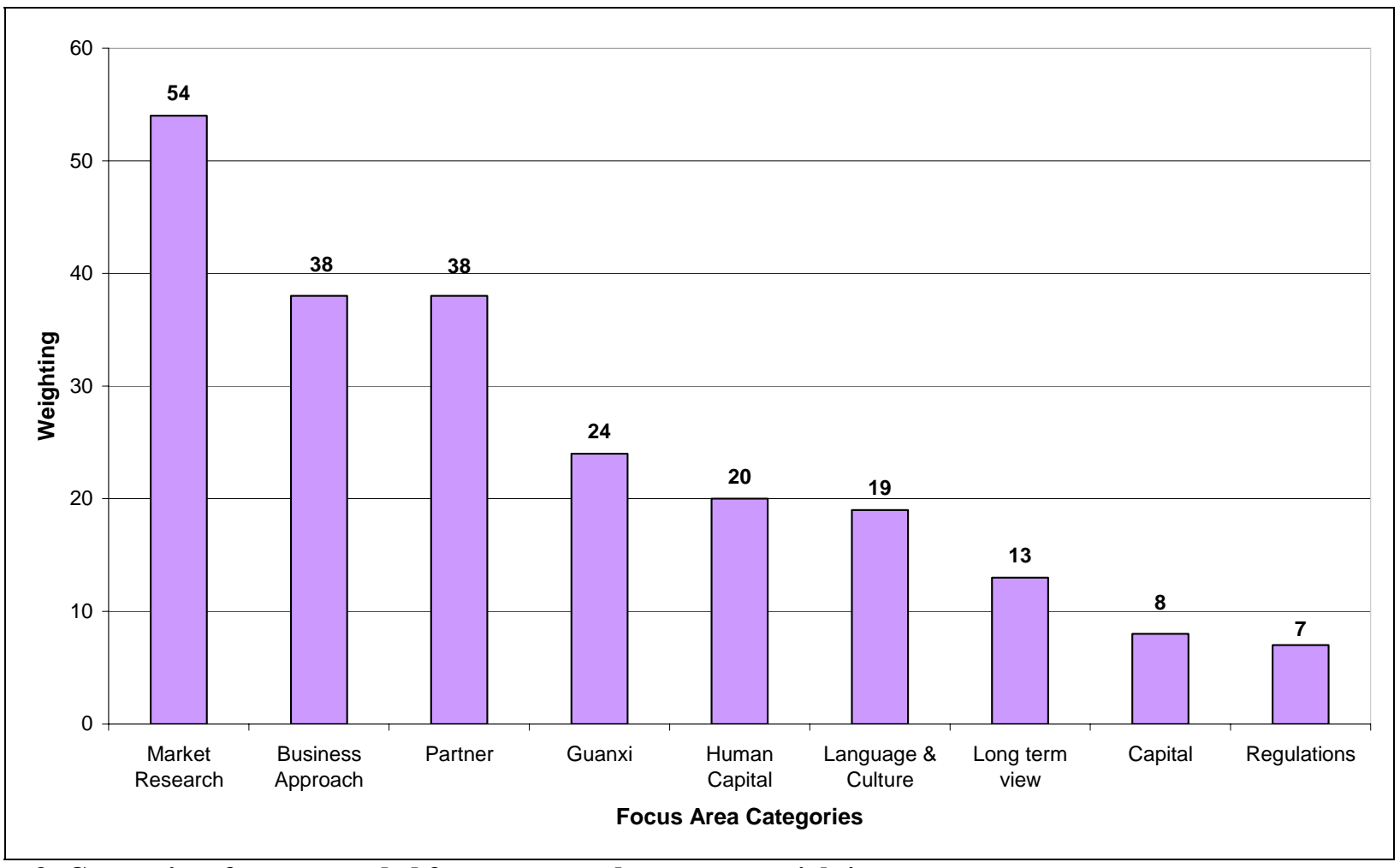

Figure 3: Categories of recommended focus areas and aggregate weightings.

Three groupings within the clusters can be distinguished. Understanding the Market, selecting the right Partner, Relationships and adapting Business Style are the most commonly recommended focus areas. These are followed by correct Staffing, Communication and Language and Product customization for the Chinese market. The last grouping is: having a Long term view, good Governance, sufficient Capital and understanding the Regulations. The Business Approach cluster refers to the unique manner/style in which business - 'a Chinese way', is identified and a key insight from this cluster of recommendations is that SA firms will need to adjust their operating style. At the same time, it is 
particularly important for management to maintain strong corporate governance, and to ensure open communication throughout the organisation.

Three respondents indicated a focus on JV partners is the most important recommendation (weighting of 5). This focus area is mentioned 11 times and is as important as a Business Approach. The individual recommendations provided relate to the importance of not only selecting the right Chinese partner, but also ensuring that a relationship of trust and understanding is fostered. The relationship cluster reinforces the importance of access to relevant stakeholders through guanxi network relationships. The Human Capital cluster is mentioned six times by respondents and covers aspects of human resources from recruitment to development; this in the context of a shift away from lifelong job tenure in the decades-old 'iron rice bowl' system (Argus, 2003). This recommendation cluster reveals the shortage of skilled locals and emphasises sound recruitment practice. Although the cluster, Language and Culture, is only referred to five times, two of these indicate that this is the most important recommendation when considering the Chinese market.

The Chinese market, due to its complexity and size, requires time. A long term view recommendation cluster is highlighted six times and shares some strategic insights regarding the time period and realistic approach that is necessary for success in the Chinese market. Two of the smallest clusters are Capital and Regulations, each with three references. The recommendation regarding Capital provides an insight into the immense size of the Chinese market. South African companies would do well to factor this into any feasibility studies. The lowest rating, recommending a focus on understanding Regulations, is in contrast with the high rating it has achieved in the Constraints section above. The reason for this anomaly is not clear and further investigation is necessary.

\section{Merits of South African business in China}

The final section of the survey allowed respondents the opportunity to share additional information they felt may be relevant to the readers of this report. Some anecdotal insights were extracted from the responses, and are presented below in appropriate categories. These included the importance of (1) 'Initiation' (most companies start in China with a representative office to develop their business before any joint ventures are established; the Chinese market cannot be entered from a distance; an ongoing presence is required as well as patience in building up contacts.); (2) governance (professionalism and ethical behaviour are as necessary as elsewhere); (3) Interaction ('face': advice cannot easily be given nor a contradiction made even when circumstances seem strange to a Westerner); (4) misconceptions or stereotypical comments ('it is dangerous to simplify China or to generalise hastily working and operating there will always be the best teacher'). Respondents were asked if or how their SA experience equipped them for working in China. The responses below are examples of tacit knowledge gained.
Perpetual change in the workplace over the last ten years has given South Africans the capacity to cope with ambiguity and non-closure. This means we're inherently well-positioned in a place like China, which is something of a moving feast - you identify goals today, and tomorrow they've moved. Ultimately it depends on you as a person, you may have a subtle advantage over expatriates from other countries, but you still need to work hard on fitting in.

Roy Bagattini, SABMiller China

South Africans are highly sought after employees globally, not just in China. Reasons being: we are 'cheap' compared to US and European equivalents; we have an incredible work ethic and do not mind twelve hour days; managers who have worked through the change of regime in SA are very culturally aware and have the experience to work respectfully with sensitive nationals.

Penny Fisher, InternationalSOS

I think South Africans may have the advantage of being more used to working with cultures different from their own. I think they tend to understand the Chinese person better, sooner - being more culturally tolerant. I mentioned this to Our President Mbeki during his visit to China in Dec 2001 and he agreed with that, even adding from his own experience. South African businesses seem to cope better than the USA or Europeans on the way Chinese conduct their businesses. I think that South Africans have a better idea about doing business in developing countries.

J.P. Mulder, Kumba Resources

South Africa has in recent years gone through a major transformation, economically, socially and politically. From a black business perspective, I definitely felt that I had an advantage as a result of our economic developments in South Africa. I could relate to the developments in the Chinese economy easier than expats from the more established economies.

Richard Julius, One Stop Services (Pty) Ltd

Difficult one to call in terms of relative merits of an SA background vs. others as it going to so greatly depend on the individual (for example I met a USA and a UK guy each of whom were fluent in written, spoken and reading Mandarin combined with a legal and business qualification in each case - very powerful to be a Western person but have a deeper ability to connect in Chinese). But in general I would say that as South Africans we seem to be more flexible, less judgmental and more adaptable as nations go most likely due to our history and especially the more recent history... I would not stretch this point too far without looking at the individual. Australian powerhouses like Fosters could not crack the Chinese market and in fact exited as I recall, whereas $S A B$ have made it - I think I would largely ascribe this to having a better product offering and business mindset for a 
developing country and being and remaining flexible - but also having good individuals to lead this charge.

\section{Bill Bryant, Sasol Chemicals Pacific}

South African firms perceive they have particular strengths for operating in China. Respondents ascribe this to: increased cultural sensitivity from experience in a multicultural society, business experience in a developing context, reasonable salary expectations, flexibility with regard to working conditions. However, as one respondent has indicated, these are generalizations, and there are likely to be exceptions, both positive and negative. The Chinese market poses something of a dilemma for any company with international ambitions - the scale of opportunities is matched only by the complexity of the challenges. Jonathon Solesbury shared some insights that explain why SABMiller is succeeding in China, where competitors have failed. He noted that conducting a thorough assessment of the market and potential partners, building a relationship network upon which to build ones business, complementing the strengths of business partner, demonstrating commitment to China at executive level and recognising SA experience as a potential source of competitive advantage, were important. The above qualitative findings strongly support the literature (Bjorkman \& Xiucheng, 2002; Stuttard, 2000). A modified table (Table 3) with groupings derived from the literature shows the factor cluster from the literature and empirical findings from this research Consideration of the four sections highlighted six common focus areas, listed according to the Recommendations ranking: Market, partnerships, guanxi, human capital, language and culture and regulations.

Table 3. Modified summary of findings

\begin{tabular}{l|l|l|l|l|l|l}
\hline Literature & Success Factors & Rating & Constraints & Rank & Recommendations & Rank \\
\hline Market & Regulations & 136 & Market Conditions & 52 & Market research & 54 \\
Regulations & Language \& Culture & 134 & Regulations & 34 & Business Approach & 38 \\
Guanxi & Partner & 133 & Language \& Culture & 34 & Partnership forming & 32 \\
Partner & Market & 130 & Partner choice & 28 & Guanxi & 30 \\
Human Capital & Guanxi & 129 & Human Capital & 26 & Human Capital & 20 \\
Language \& Culture & Long-term View & 117 & Guanxi & 25 & Language \& Culture & 19 \\
Head Office & Capital Input & 98 & Legal Aspects & 12 & Long term view & 13 \\
Business Approach & Human Capital & 97 & Resources & 4 & Capital access & 8 \\
Long-Term View & Technology & 89 & Credibility & 3 & Regulations & 7 \\
\hline
\end{tabular}

* items common to all four sections are shaded

The research proposition that the perspectives presented in literature, regarding focus areas for foreign companies in China, are consistent with perspectives of SA firms in China is supported. Analysis of the findings shows a high degree congruence between these findings and the literature (Stuttard, 2000; Wong \& Maher, 1997). Each section identified nine focus areas and six of these were common to all sections, including the literature and all sections of the research.

\section{Conclusions: managerial and research implications}

Foreign companies expecting to perform in China will increasingly need to recruit and develop quality local staff and managers. The most effective way of achieving this is by offering a highly competitive salary and good career prospects. These recommendations are not unique to China. Large numbers of overseas-trained nationals are returning, with many Chinese students having done an MBA and other business courses. Economic reforms and the influx of multinationals are bringing a more strategic approach to human resource management in China, with a greater emphasis on merit-based recruitment and career development. An important lesson is to ensure that employees recruited by a joint venture partner are often willing to receive incentive pay.

Fostering a culture of critical thinking and risk-taking prevalent in multinationals is becoming less foreign. The need for skills development amongst Chinese managers provides an excellent opportunity for crossvergence - crosscultural diffusion of high performance work practices from SA (Horwitz et al., 2002). This concurs with Zhu, de Cieri and Dowling's (3003) conclusion that whilst there is evidence of convergence of HR practices, (specific Chinese practices like labour allocation, output quotas in job analysis and administrative-oriented performance appraisal, remain widely used), it is still premature to pronounce that HR practices in China have definitely moved closer to a Western style of HRM.

The level of training required is costly, but this must be weighed against the significant cost of expatriate managers, from relocation costs to 'hardship' premiums, increasing turnover of local professionals and an associated challenge of staff retention through careful selection, education, coaching and career development paths. The fact that inexperienced expatriates are responsible for the most number of corporate failures in China reinforces this message. Contributing to this is a work culture vastly different from that of their home countries. Concepts such as face, guanxi and quo qing are integral to Chinese business and the inability of companies to master these differences can result in time-consuming negotiations, communication problems and misunderstandings.

The complexity of operating in the Chinese market requires a clear long term focus that is supported internally. Short term profits may be sacrificed as companies build the 
networks and local human capital through skills formation, competency training and technology transfer - these being necessary for long term firm success in the Chinese labour and product markets. There is a need to be patient but preparedness to move quickly when required. Firms can play an active role in shaping the forces that drive changes, thereby obtaining first mover advantage. Strong financial support is needed to withstand the uncertainty and intense competition that is evident and has a negative effect on profits. A good exit strategy should also be put in place. Ultimately, the consensus is that China is a market with huge potential for profits albeit in the long term, and that foreign firms need to take a phased approach to building market and organisational effectiveness (Lieberthal \& Lieberthal, 2003: 77-78).

Our findings offer a basis for further research using quantitative analytical techniques. It is recommended that certain key focus areas identified, be investigated further to establish statistical significance, and the strength of interrelationships between them. For example, the need for skills development amongst Chinese managers and professionals provides an excellent opportunity for the diffusion of successful work practices applied in SA. But Western style management practices need to be adapted for host county employees. Investment in training has to be weighed against the high cost of expatriate employees. Strategies for attraction, development and retention of human capital are becoming more relevant in China as turnover of qualified staff increases. The workplace system of 'iron rice bowl' lifelong employment is making way for market-orientated labour policies with individual employment contracts and a work ethic that encourages initiative and entrepreneurship. South African firms have particular strengths in operating in this developing market.

\section{References}

Abramson, N.R. \& Ai, J.X. 1999. 'Canadian companies doing business in China: Key success factors’, Management International Review, 39 (1):7-35.

Agenbag, E.H.G. 2001. 'A critical review of the market entry mode decision of foreign investors in the People's Republic of China'. Masters thesis, Dept. of Commerce, University of Stellenbosch.

Argus, 2003. ‘China to phase out jobs for life’. 7 March:4.

Björkman, I. \& Xiucheng, F. 2002. 'Human resource management and the performance of Western firms in China', International Journal of Human Resource Management, 13(6):853-864.

Brandenburger, A.M. \& Nalebuff, B.J. 1995. 'The right game: Use game theory to shape strategy', Harvard Business Review, July-August: 57-71.

Cape Times Business Report. 2003. 'China and Africa plan to triple trade', 15 December: 20.
Chen, C. \& Godkin, L. 2001. 'Mianzi, Guanxi and Western prospects in China', International Journal of Management 18(2):139-145.

Chinese Embassy. 2002. 'Sino-South African bilateral economic and trade cooperation', [online] URL: http://www.chinese-embassy.org.za/eng/13599.html. Accessed 8 July 2002.

Chiu, W.C.K. 2002. 'Do types of economic ownership matter in getting employees to commit? An exploratory study in the People's Republic of China', International Journal of Human Resource Management 13(6):865-882.

Horwitz, F.M., Kamoche, K. \& Chew, I.K.H. 2002. 'Looking east: Diffusing high performance work practices in the southern Afro-Asian context', International Journal of Human Resource Management, 13(7):1019-1041.

Ji, L. 2003. 'Strategic human resources and MNE's performance in China', International Journal of Human Resource Management, 14(2):170.

Landry, J.T. 1997. 'China: Put people first', Harvard Business Review, 75(5):8-9.

Leedy, P.D. 1993. Practical research, planning and design. New York: Macmillan Publishing Co.

Lieberthal, K. \& Lieberthal, G. 2003. 'The great transition', Harvard Business Review 81(10):1-2.

Ma, Z., Wang, X., Jaeger, A., Anderson, T., Want, Y. \& Saunders, D. 2002. 'Individual perception, bargaining behaviour, and negotiation outcomes - a comparison across two countries', International Journal of Cross Cultural Management 2(2):171-184.

Mok, K., Wong, L. \& Lee, G.O.M. 2002. 'The challenges of global capitalism: Unemployment and state workers' reactions and responses in post-reform China', International Journal of Human Resource Management 13(3):399-415.

Morgan Stanley Capital International INC. 2003. Reported by Shevel, A., in Sunday Business Times, 17 July:3.

Morrison, T. Conaway, W.A. \& Douress, J. J. 2001. Dun \& Bradstreet's guide to doing business around the world. United States: Prentice Hall.

Ogilvy, J., Schwartz, P. \& Flower, J. 2000. China’s futures. San Francisco: Jossey-Bass Publishers.

Pitta, D.A., Fung, H. \& Isberg, S. 1999. 'Ethical issues across cultures: Managing the differing perspectives of China and the USA' Journal of Consumer Marketing, 16(3):240-256.

Price Waterhouse Coopers. 2002. 'China in the next three to five years...’ Pulses, July: 6-10.

Saunders, M., Lewis, P \& Thornhill, A. 1997. Research methods for business students. London: Pitman Publishing. 
Schiller, S. 2001. 'The effects of Chinese learning on the efficiency of organizational strategies: An analysis', International Journal of Management 18(3):369-375.

Selmer, J. 2002. 'To train or not to train? European expatriate managers in China', International Journal of Cross Cultural Management, 2(1):37-51.

Stuttard, J.B. 2000. The new silk road. New York: John Wiley \& Sons, Inc.

The Economist Intelligence Unit. 2001. 'How to win in China', Business Asia, 11 June:2-5.

Tsang, E.W.K. 1998. 'Can guanxi be a source of sustained competitive advantage for doing business in China?' Academy of Management Executive 12(2):64-74.

Usunier, J-C. 1998. International \& cross-cultural management research. London: Sage Publications.

Warner, M., Goodall, K. \& Ding, D.Z. 2002 'Implementing China's people-management reforms'. In Warner, M. \& Joynt, P. (Eds.). Managing across cultures. London: Thomson Learning, pp. 168-177.

Wells, L.F. 1996. Selling to the world. New York: McGrawHill.

Whiteley, A. 1998. 'Keys uncovered to foreign business success in China'. [online] URL:

http://announce.curtin.edu.au/release1998/c4498.htm.

Accessed 5 June 2002.

Wong, Y.Y. \& Maher, T.E. 1997. 'New key success factors for China's growing market’, Business Horizons 40(3):4353.

Wong, Y.Y. 1995. 'Succeeding in China in the $21^{\text {st }}$ Century', S.A.M. Advanced Management Journal, 60(3):4-9.

World Bank. 2002. 'China at a glance', [online]URL:

http://www.worldbank.org/data/countrydata/aag/chn_aag.pdf. Accessed 20 November 2002.

Xiao, J., \& Lo, L.N.K. 2003. 'Human capital development in Shanghai: Lessons and prospects', International Journal of Educational Development, 23: 411-412.

Yan, R. 1994. 'To reach China's consumers, adapt to Guo Qing', Harvard Business Review, September - October: 6675.

Zeng, M. \& Williamson, P.J. 2003. 'The hidden dragons', Harvard Business Review, 81(10):92-93.

Zhu, C.J. \& Dowling, P.J. 2002. 'Staffing practices in transition: some empirical evidence from China', International Journal of Human Resource Management 13(4):569-597.

Zhu, C.J., de Cieri, H., \& Dowling, P. 2003. 'Strategic human resource management in China'. Proceedings of the $7^{\text {th }}$ Conference on International Human Resource Management, 4-6 June, University of Limerick, Ireland, p15. 